\title{
A 3' SPLICE SITE CONSENSUS SEQUENCE MUTATION IN THE INTRON 3 OF THE $\alpha$-GALACTOSIDASE A GENE IN A PATIENT WITH FABRY DISEASE
}

\author{
Tohru YokoI, Kazuko SHINoda, Ichiro OhNo, Kimitaka Kato, \\ Toshio MIYaWaki, and Noboru TANIGUCHI \\ Department of Pediatrics, School of Medicine, Kanazawa University, \\ 13-1 Takara-machi, Kanazawa, Ishikawa 920, Japan
}

\begin{abstract}
Summary Fabry disease is an X-linked disorder accompanied with accumulation of glycosphingolipids resulting from the deficient activity of the lysosomal hydrolase, $\alpha$-galactosidase A $(\alpha-\mathrm{GalA})$. In the present study, mRNA for $\alpha$-GalA in fibroblasts from an 11-year-old Japanese patient with Fabry disease was examined using the reverse transcriptasepolymerase chain reaction (PCR). The shorter message of $\alpha$-GalA was demonstrated in this patient when compared with the normal control. The complete deletion of exon 4 in the mRNA for $\alpha$-GalA in the patient was disclosed by analysis of cDNA with restriction enzyme digestion and asymmetrical PCR sequencing. The direct sequencing of the genomic DNA demonstrated a single base substitution $(\mathrm{G} \rightarrow \mathrm{A})$ at the $3^{\prime}$ end of the consensus sequence of intron 3. This mutation destroyed a splice site in the $\alpha$-GalA, which produced a mutant allele. It was also shown that the mother of the patient had this mutant as well as normal alleles as a heterozygote.
\end{abstract}

Key Words $\quad$ Fabry disease, $\alpha$-galactosidase A, point mutation, splicing mutation, RT-PCR analysis

\section{INTRODUCTION}

Fabry disease is an X-linked recessive disorder with a defect in activity of the lysosomal hydrolase, $\alpha$-galactosidase A ( $\alpha$-GalA) [EC 3.2.1.22]. Recently, the full-length cDNA encoding human $\alpha$-GalA has been isolated and characterized (Calhoun et al., 1985; Bishop et al., 1986, 1988; Kornreich et al., 1989). Since then molecular analysis of this disease has been reported. Various types of deletion of genomic DNA were found in about $5 \%$ of patients (Bernstein et al., 1989)

Received June 18, 1991, revised version received July 11, 1991, Accepted July 17, 1991. 
and point mutations have been reported from the rest of patients (Bernstein et al., 1989; Koide et al., 1990; Sakuraba et al., 1990).

In this study, we reported the first case of Fabry disease who had a 3' splice site consensus sequence mutation in the intron 3 of his $\alpha$-GalA gene. The sequence analysis also revealed that his mother carried the point mutation as a heterozygote.

\section{MATERIALS AND METHODS}

The patient was a 11-year-old Japanese boy, suffering from abdominal pain, general malaise, acroparesthesias, angiokeratoma, hypertension, and corneal opacities. The activities of $\alpha$-GalA of plasma and his cultured fibroblast were undetectable. Skin fibroblast cultures were established by the conventional techniques.

Preparation of RNA and cDNA was mentioned elsewhere (Kasahara et al., 1990). Briefly, RNA was extracted from confluent fibroblasts by the single step method (Piotr and Nikoletta, 1987). After the conversion of the mRNA into cDNA by RAV-2 reverse transcriptase (Takara Shuzo Co., Kyoto, Japan), cDNA was passed through a spun column of Sephadex G-50 (Pharmacia-LKB Biotechnology, Uppsala, Sweden), and was then used as a template for PCR.

The sequences of oligonucleotide primers AGl, AG3, AG4, AG5, and AG7 were shown in Table 1. The locations of those primers were shown in Fig. 1. These primers were designed on the basis of the reported sequence data (Bishop et al., 1986; Kornreich et al., 1989).

DNA Thermal Cycler (Perkin Elmer-Cetus, Norwalk, CT, U.S.A.) was used for 40 cycles of appropriate temperature control followed by incubation at $72^{\circ} \mathrm{C}$ for $7 \mathrm{~min}$.

A protein coding region of cDNA from the fibroblasts was amplified by the PCR with primers AG1 and AG3. The amplified product was purified and digested with MboI or PvuII (Takara Shuzo Co.). Complementary DNA between exon 3 and exon 5 was amplified with primers AG4 and AG5.

Table 1. Sequences of primers.

\begin{tabular}{lllr}
\hline Primer & \multicolumn{1}{c}{ 5'-Sequence -3' } & \multicolumn{1}{c}{$\begin{array}{l}\text { Corresponding } \\
\text { nucleoride }\end{array}$} & Exon \\
\hline AG1 & AAGTAAGTCTTTTAATGACATCTG & $\# 1194-\# 1171$ & 7 \\
AG3 & CTGGACAATGGATTGGCAAGGACG & $\# 1-\# 24$ & 1 \\
AG4 & GCTGACTGGGGAGTAGATCT & $\# 385-\# 404$ & 3 \\
AG5 & CTGGTCCAGCAACATCAACA & $\# 685-\# 666$ & 5 \\
AG7 & AAGAGGCCACTCACAGGAGTA & $\# 525-\# 505$ & 4 \\
\hline
\end{tabular}

a cDNA nucleotide number shown here is by Bishop et al. (1986). 
To analyze genomic DNA for $\alpha$-GalA, high molecular weight DNA was prepared from leukocytes of the patient, the mother of the patient and healthy male volunteer. One microgram ofge no micDNA from patient and control were amplified with AG4 and AG5.

An aliquot of cDNA was amplified with $1 \mu \mathrm{M}$ each of primer AG4 and AG5 for 25 cycles. Subsequently, one-fiftieth of the product was amplified farther for 25 cycles with excess of primer AG5 to AG4 (40:1). The product was extracted with phenol/chloroform, then the residual primers were removed by ultrafiltration (Centricon-100TM; Grace Japan KK-Amicon, Tokyo, Japan). The sequencing reaction was done using Taq sequencing kit (Takara Shuzo Co.) with ${ }^{32}$ P-labeled primer AG4. The sequence from the opposite side was done by the same way with just exchanging primers. Genomic DNA was sequenced in the same method except for primers AG4 and AG7.

\section{RESULTS}

Shorter message of $\alpha$-galactosidase A in the fibroblast from a patient with Fabry disease

Figure 1 shows the structural organization of the $\alpha$-GalA gene, restriction site of $M b o I$ and $P v u I$ in $\alpha$-GalA cDNA and the locations of primers. RT-PCR analysis with primers $A G 1$ and $A G 3$ revealed a protein encoding $1.2 \mathrm{~kb}$ band of cDNA

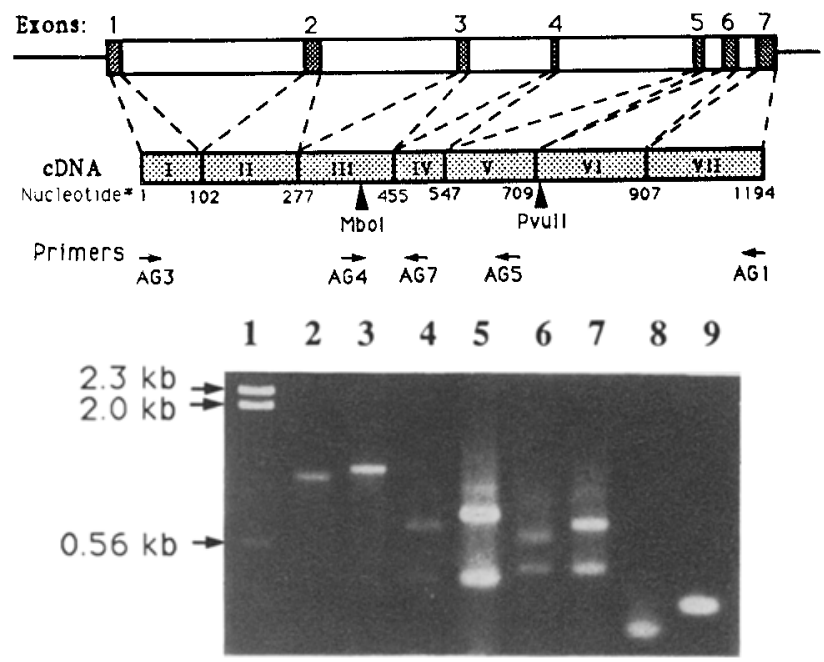

Fig. 1. The structural organization of the $\alpha$-GalA gene; exon composition and restriction sites of $M b o \mathrm{I}$ and $P v u \mathrm{II}$, the locations of primers and RT-PCR analysis of $a$-GalA cDNA from the Fabry disease patient and control. cDNA nucleotide numbers shown here were defined by Bishop et al. (1986). Lane 1, $\lambda$ HindIII; lanes 2, 4, 6 and 3,5, 7 were patient's and control's cDNA amplified with primers AG1 and AG3, respectively. Lanes 2 and 3 were amplified product uncut; lanes 4 and 5, MboI digest; lanes 6 and 7,PvuII digest. Lanes 8 and 9 were amplified cDNA with primers AG4 and AG5, patient and control, respectively. 
of $\alpha$-GalA from control, but a shorter message of $\alpha$-GalA was seen in the patient than in the normal control (Fig. 1, lanes 2 and 3). These products were purified and digested with $M b o I$ or $P v u I I$ to detect the point of the deletion. Digestion of control cDNA showed $0.8 \mathrm{~kb}$ and $0.4 \mathrm{~kb}$ bands by $M b o \mathrm{I}$, and $0.73 \mathrm{~kb}$ and $0.47 \mathrm{~kb}$ bands by $P v u I I$. In the case of patient cDNA, although short bands remained at the same size as control, long bands were shortened in both digestion (Fig. 1, lanes 4-7). The PCR products of cDNA with primers AG4 and AG5 revealed that the distance of exon 3 and exon 5 in cDNA from the patient was about 90 bp shorter than that from control. Because the length of exon 4 is 92 bases long, total deletion of exon 4 in the patient cDNA was suspected.

The sequencing result of cDNA was shown in Fig. 2. When compared with reported sequence, it was suggested that exon 4 was totally skipped, and exon 3 connected to exon 5 directly in patient's cDNA.

Analysis of splicing donor and splicing acceptor sites of intron 3

Although DNA deletion including exon 4 was suggested, genomic DNA bands by PCR with primers AG4 and AG5 showed $2.9 \mathrm{~kb}$ distinct band and there was no difference in length between the patient and control DNA, and further PCR amplification of genomic DNA with primers AG4 and AG7 showed the same distinct bands in both control and the patient (data not shown). These results confirmed that there was no large DNA deletion including exon 4 in this patient.

Asymmetrical PCR and sequencing experiments with primers AG4 and AG7 for both direction were executed to investigate $5^{\prime}$ end (splicing donor) and $3^{\prime}$ end

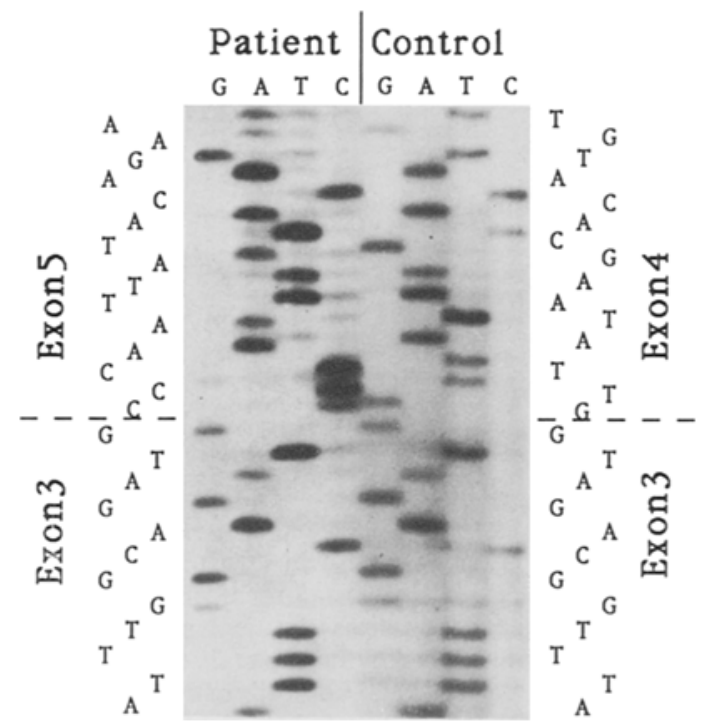

Fig. 2. Sequencing gel showing deletion of exon 4 in the cDNA from the patient with Fabry disease. 


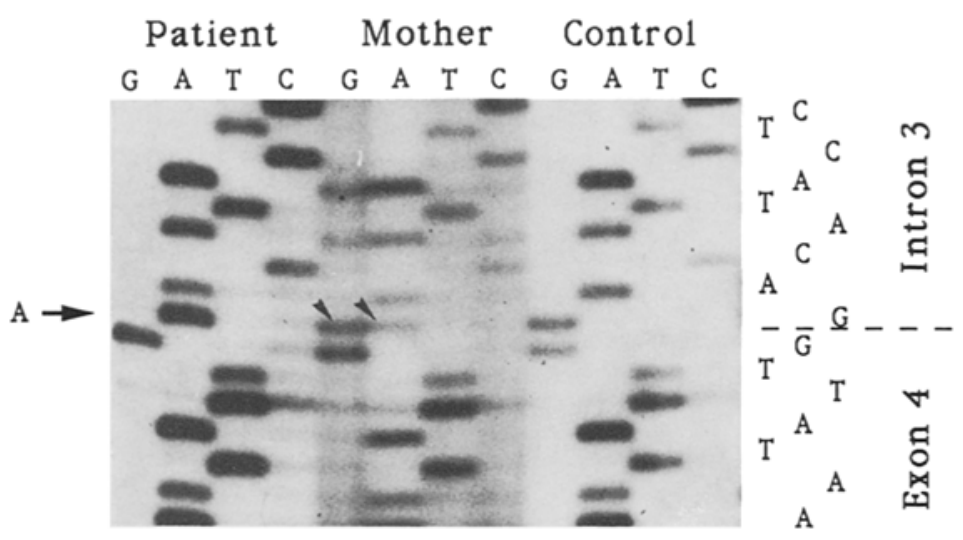

Fig. 3. Sequencing gel showing a base substitution $(G \rightarrow A)$ at the 3 ' splice site consensus sequence in the genomic DNA from the Fabry disease patient. Both normal and mutant alleles were detected in genomic DNA of the mother (arrows).

(splicing acceptor) of intron 3. We were able to identify a particular nucleotide change $(\mathrm{G} \rightarrow \mathrm{A})$ located at the $3^{\prime}$ end consensus sequence of intron 3 (Fig. 3). Sequencing of maternal chromosome allowed us to locate the same mutant allele was carried by maternal chromosome as a heterozygous carrier. Both $\mathrm{G}$ and $\mathrm{A}$ nucleotide bands were observed at the same position (arrows in Fig. 3). Except for this point, there was no difference among sample around $3^{\prime}$ region of intron 3. There was no difference in splicing donor site between patient and control (data not shown). The sequence result of at least 100 bases of the $5^{\prime}$ end of intron 3 matched to the previous report (Bishop et al., 1988; Kornreich et al., 1989).

\section{DISCUSSION}

In an 11-year-old young patient of Fabry disease, the deletion of exon 4 in the $\alpha$-GalA mRNA was observed, which induced a frame shift thereafter and an appearance of terminating codon in exon 5 . Our data strongly suggested that the $\mathrm{G} \rightarrow \mathrm{A}$ point mutation destroyed the critical consensus sequence in $3^{\prime}$ end of intron 3 and therefore splicing acceptor site of intron 4 was alternatively activated followed by processing of abnormal mRNA with complete deletion of exon 4 .

Since cDNA of $\alpha$-GalA was cloned and characterized (Calhoun et al., 1985; Bishop et al., 1986), molecular abnormalities in more than one hundred families with Fabry disease have been studied. Bernstein et al. (1989) reported that partial gene deletions were seen only seven families out of 130 families by Southern blotting analysis. They also reported a point mutation $(\mathrm{C} \rightarrow \mathrm{T})$ detected by $M s p I$ digestion of the genomic DNA PCR product. Other researchers reported a deletion of exon 3 caused by genomic DNA rearrangement (Fukuhara et al., 1990) and some point mutations which induced single amino acid substitution critical for secondary structure of $\alpha$-GalA (Koide et al., 1990; Sakuraba et al., 1990). Sakuraba also reported 
a family with a shorter message of $\alpha$-GalA due to a point mutation at the $5^{\prime}$ splice site of intron 6 (Sakuraba, 1989).

The single nucleotide mutations in the $3^{\prime}$ end of introns have been reported on $\beta$-thalassemia gene (Treisman et al., 1983) and cystic fibrosis gene (Guillermit et al., 1990) but not on $\alpha$-GalA gene. As far as we know, this is the first case with the abnormal mRNA caused by $3^{\prime}$ splice site point mutation in $\alpha$-GalA gene.

Acknowledgments This work was supported in part by Grant-in-Aid for Scientific Research from the Ministry of Education, Science and Culture of Japan.

We would like to thank Drs. Norihiko Okuda and Chiharu Kanegane (Kanazawa National Hospital) for referring the patient. Appreciation is also extended to Drs. Kazuo Yamaguchi and Yoshinobu Nakanishi (Kanazawa University) for their technical suggestions.

\section{REFERENCES}

Bernstein, H.S., Bishop, D.F., Astrin, K.H., Kornreich, R., Eng, C.M., Sakuraba, H. and Desnick, R.J. 1989. Fabry disease: Six gene rearrangements and an exonic point mutation in the $\alpha-$ galactosidase gene. J. Clin. Invest. 83: 1390-1399.

Bishop, D.F., Calhoun, D.H., Bernstein, H.S., Hantzopoulos, P., Quinn, M. and Desnick, R.J. 1986. Human $\alpha$-galactosidase A: Nucleotide sequence of a cDNA clone encoding the mature enzyme. Proc. Natl. Acad. Sci. U.S.A. 83: 4859-4863.

Bishop, D.F., Kornreich, R. and Desnick, R.J. 1988. Structural organization of the human $\alpha$ galactosidase A gene: Further evidence for the absence of a $3^{\prime}$ untranslated region. Proc. Natl. Acad. Sci. U.S.A. 85 : 3903-3907.

Calhoun, D.H., Bishop, D.F., Bernstein, H.S., Quinn, M., Hantzopoulos, P. and Desnick, R.J. 1985. Fabry disease: Isolation of a cDNA clone encoding human a-galactosidase A. Proc. Natl. Acad. Sci. U.S.A. 82: 7364-7368.

Fukuhara, Y., Sakuraba, H., Oshima, A., Shimmoto, M., Nagao, Y., Nadaoka, Y., Suzuki, T. and Suzuki, Y. 1990. Partial deletion of human $\alpha$-galactosidase A gene in Fabry disease: Direct repeat sequences as a possible cause of slipped mispairing. Biochem. Biophys. Res. Commun. 170: 296-300.

Guillermit, H., Fanen, P. and Ferec, C. 1990 . A $3^{\prime}$ splice site consensus sequence mutation in the cystic fibrosis gene. Hum. Genet. 85: 450-453.

Kasahara, Y., Miyawaki, T., Kato, K., Kanegane, H., Yachie, A., Yokoi, T. and Taniguchi, N. 1990. Role of interleukin 6 for differential responsiveness of naive and memory CD4 $+\mathrm{T}$ cells in CD2- mediated activation. J. Exp. Med. 172: 1419-1424.

Koide, T., Ishiura, M., Iwai, K., Inoue, M., Kaneda, Y., Okada, Y. and Uchida, T. 1990. A case of Fabry's disease in a patient with no $\alpha$-galactosidase A activity caused by a single amino acid substitution of Pro-40 by Ser. FEBS L.ett. 259: 353-356.

Kornreich, R., Desnick, R.J. and Bishop, D.F. 1989. Nucleotide sequence of the human $\alpha$-galactosidase A gene. Nucleic Acids Res. 17: 3301-3302.

Piotr, C. and Nikoletta, S. 1987. Single-step method of RNA isolation by acid guanidinium thiocyanate-phenol-chloroform extraction. Anal. Biochem. 162: 156-159.

Sakuraba, H. 1989. Molecular genetics of Fabry disease. Seikagaku (in Japanese) 61: 294-299.

Sakuraba, H., Oshima, A., Fukuhara, Y., Shimmoto, M., Nagao, Y., Bishop, D.F., Desnick, R.J. and Suzuki, Y. 1990. Identification of point mutations in the $\alpha$-galactosidase A gene in classical and atypical hemizygotes with Fabry disease. Am. J. Hum. Genet 47: 784-789.

Treisman, R., Orkin, S.H. and Maniatis, T. 1983. Specific transcription and RNA splicing defects in five cloned $\beta$-thalassaemia genes. Nature 302: 591-596. 